\title{
Salvaging a hopeless tooth by perio-prostho approach: A clinical report
}

\author{
Khalid Gufran ${ }^{1}$, Mohammed Alasqah ${ }^{1}$, Tushar Vithalrao Bhagat ${ }^{2}$, Mariam Omer Bin Hamza ${ }^{3}$ and Ashwini Nareshchandra Walke ${ }^{4 *}$ \\ ${ }^{1}$ Department of Preventive Dental Sciences, College of Dentistry, Prince Sattam Bin Abdul Aziz University, AlKharj, Kingdom of Saudi Arabia \\ ${ }^{2}$ Department of Prosthodontics, College of Dentistry, Prince Sattam Bin Abdul Aziz University, AlKharj, Kingdom of Saudi Arabia \\ ${ }^{3}$ Alkharj Armed Forces Hospital, Kingdom of Saudi Arabia \\ ${ }^{4}$ Consultant, Prime Dental Care, Pune, India
}

\begin{abstract}
This report describes management of furcal perforation in mandibular first molar by bicuspidization and regeneration of bone using an osseograft. 45 years male individual was reported having inflammation in the right mandibular posterior region of the jaw with periodic exacerbation and remission. On examination, sinus opening was found in relation to buccal side of 46 . Radiographic examination revealed radiolucency and radio-opaque mass in the furcation area of 46 suggestive of foreign body. The patient was diagnosed of primary endodontic involvement with secondary periodontal lesion of tooth 46 . Antibiotic coverage followed by abscess drainage of 46 was done. Surgical procedure was scheduled with bicuspidizaton technique and bone grafting. After the thorough debridement, the furcation defect was filled with an osseograft. Subsequently, 6 week later, toot preparation for porcelain fused to metal restorations was performed on dissected portions. Post operatively, the patient follow up was done at $1^{\text {st }}$ month, $2^{\text {nd }}$ month and $6^{\text {th }}$ month.
\end{abstract}

\section{Introduction}

Pathologic or iatrogenic links between root canal and periodontal apparatus are called as perforations. The main cause of perforations is uncontrolled removal of tooth structure during access cavity preparation \& locating canal orifices [1-3]. Compromization in conservative approach for post space preparation of root canal treated tooth is one more cause for root perforation [2]. Strip-perforation can also occur accidentally during negotiation during curved canals, canals which are having calcification and while lateral extension technique during endodontics rehabiliitation [4]. Floor at the furcation area sometimes meet accidental perforation while locating orifices. Perforations can be treated using biocompatible sealant forming a hermetic seal, if it is not disturbed by existing restoration material [5]. However, if the former is not the case then surgical access becomes imperative for irritants elimination from the fornix. Furcations are difficult to access using non-surgical techniques for removal of irritants [6]. Henceforth, surgical flaps is obligatory [7]. Resection techniques like amputation of root, bicuspidization, hemisection and radisection techniques are other options to treat furcation [8].

Bacterial infection of the pulpal or periodontal tissues deayed healing along with inflammatory sequels like suppurations causing teeth tenderness followed by abscesses \& fistulae along with resorption of bone [9]. When multi-rooted teeth are affected by perforation accidentally at crestal level gingival epithelium down-growth can occur at perforation site [10].

This case report describes furcal perforation and in mandibular first molar, which was treated by bicuspidization and regeneration of bone which was lost in the furcation area due to perforation.

\section{Clinical report}

A 45-year-old male patient was presented with a complaint of swelling in the right lower back region of the jaw with periodic exacerbation and remission to the clinic, College of Dentistry, Prince Sattam Bin Abdulaziz University, Alkharj, Saudi Arabia. Detailed history of the patient revealed that endodontic treatment was done by private practitioner 3 years ago with respect to tooth 46 . There was no relevant medical history.

Intra-oral examination of the patient revealed good oral hygiene. Tooth 46 was periodontally sound with no mobility or attachment loss. Sinus opening was seen in the buccal aspect of tooth 46 . On radiographic examination, (Figure 1) sinus tracking was done using gutta percha with the tip of gutta purcha pointing towards the furcation area. Radiolucency was observed in the furcation area. Also, a radioopaque mass suggestive of foreign object was observed in the furcation area of 46 .

The obturation of the root canal was found to be satisfactory. The patient was diagnosed with primary endodontic with secondary periodontal lesion of tooth 46 . The treatment protocol was as follows:

${ }^{\star}$ Correspondence to: Ashwini N Walke, Consultant, Prime Dental Care, Pune, India, E-mail: ashwiniwalke2210@gmail.com

Key words: bicuspidization, furcation, osseograft, periodontics, prosthodontics

Received: October 25, 2018; Accepted: November 12, 2018; Published: November 15, 2018 


\section{Preliminary phase}

Abscess drainage under local anaesthesia was performed. Then the patient was prescribed amoxicillin clavulanic acid $625 \mathrm{mg}$ in order to eradicate acute infection and recalled after 2 weeks.

\section{Phase I therapy}

Full mouth oral prophylaxis was performed. $0.2 \%$ chlorhexidine twice a day for one week was advised.

\section{Phase II therapy}

Surgical procedure was scheduled with bicuspidizaton technique and bone grafting. Inferior alveolar nerve blocked by $2 \%$ Lignocaine with 1:80,000 Adrenaline. The reflected flap was full thickness flap by a crevicular incision that was spread distal of 45 to the mid surface of 47. Subsequently, flap reflected followed by dissecting the tooth and the restorative surplus was removed from the furcation (Figure 2). After the surgical debridement the furcation defect was filled with an osseograft (Figure 3). Before placing periodontal dressing interrupted sutures were used at the surgical spot.

\section{Phase III therapy}

Six weeks later the tooth was prepared for porcelain fused to metal restorations, with shoulder finish margin buccally and chamfer lingually. After gingival retraction, final impression was made with polyvinysiloxane impression material. In work authorization form for the dental laboratory, special mention about the provision of space in between mesial and distal root was done (Figures $4 \& 5$ ). This space is the key factor to maintain the periodontal health of the roots as it will allow the effective cleaning by interdental brush. After cementation, demonstration regarding the maintenance of oral hygiene in inter-root

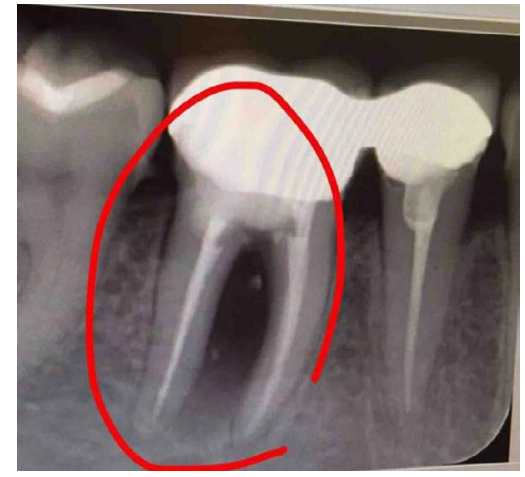

Figure 1. Pre-operative radiograph showing bone loss

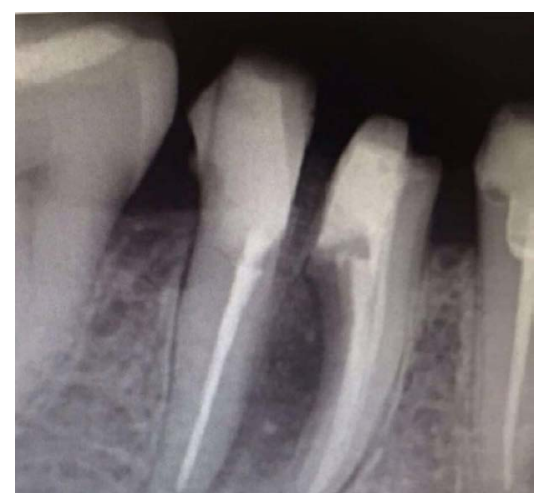

Figure 2. Radiographic presentation after bicuspidization and bone grafting

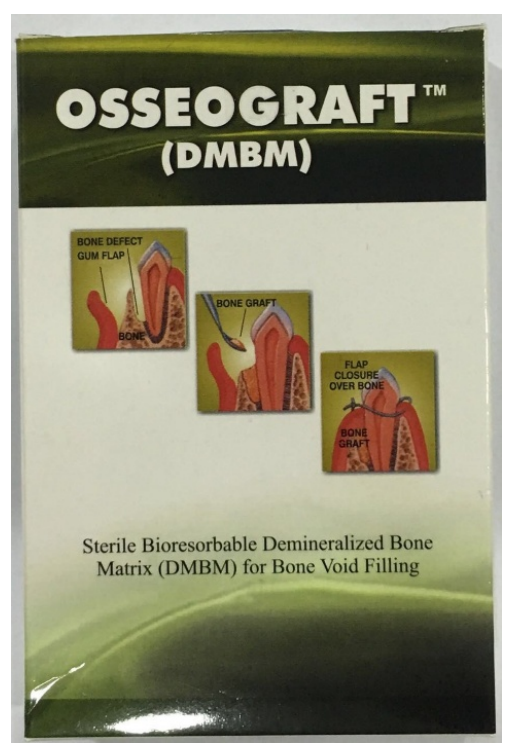

Figure 3. Bone grafting material used for the case

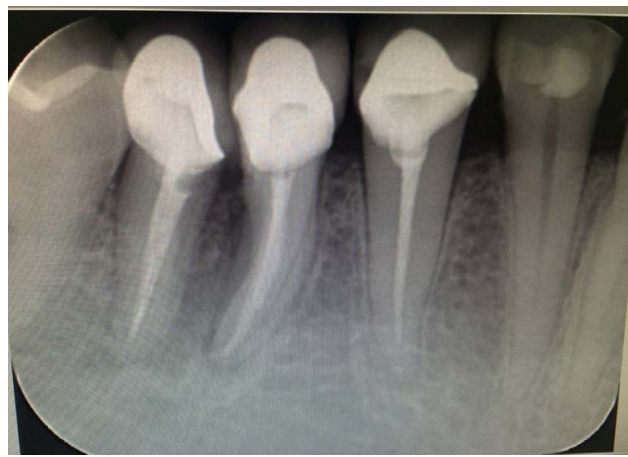

Figure 4. Post-operative radiograph showing bone fill

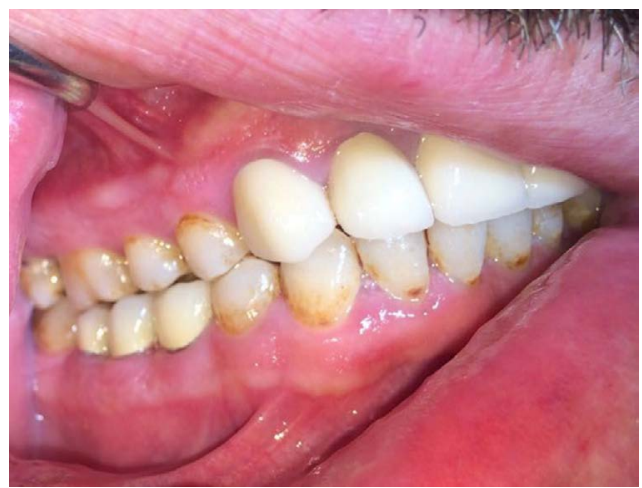

Figure 5. Post-operative photograph with prosthesis

area was done. For maintenance, the patient was recalled 1, 3 and 6 month post operatively for follow up.

\section{Phase IV}

The patient was kept on maintenance and followed up for 6 months.

\section{Discussion}

This case report describes management of furcal perforation in mandibular first molar by bicuspidization and regeneration of bone using an osseograft. 
For huge perforations due to resorption, compromised healing after non-surgical repair, when concomitant management of the periodontium is indicated, large overfilling of the defect \& nonsurgically inaccessible perforations, extensive coronal restorations can be manage by surgical intervention [3,11-13]. Tight and permanent seal avhivement is the primary goal of this surgical intervention, this ensure prevention of entry of bacteria \& byproducts in the root canal \& into the surrounding periodontium $[14,15]$.

Rud, et al. found [15] that subsequent to fixing root aperture somewhere else with dentin-reinforced resin-composite (Retroplast), bone recovered and a periodontal ligament space was mostly framed with a lamina dura against the material. Whereas, Oswald [16] stated crestal perforations surgical healing will in all likelihood ended in lost epithelial attachment and pocket development. Guided tissue regeneration has been utilized for the management of perforations and offers the likelihood of effective repair by serving as a hindrance for apical relocation of epithelium [17,18].

Furcation occurred accidentally are result of endodontic treatment complications \& frequently effecting longstanding prognosis of the tooth $[19,20]$. In any case, instrumentation \& non-biocompatible filling materials resulted in furcation the prognosis of the tooth will vitally reduced, and coronal approach tactics without surgical access will be jeopardized [21]. Periodontal tissue destruction may proceed reckless resulting in perforation at furcation posteriors preferably. Nonetheless, treatment of such cases, if done properly, will lead to a good prognosis [21].

Bicuspidization is advocated for Class II \& III situations. Also, it is the preferred technique for non-repairable perforation \& at irretrievable material site in the furcation [21]. However, bicuspidization should be performed only if the roots are periapically healthy and their lengths are adequate [22]. Farshchian and Kaiser [23] expressed, achievement of bicuspidization relies on 3 primary components: (i) satisfactory bone provision for the tooth sections; (ii) absence of severe fluting of the mesial part of the distal root or the distal aspect of the mesial root or; (iii) acceptable separation of the roots enabling the formation of an embrasure that allows proper oral hygiene maintenance. In this case, the bicuspidization technique was pervormed because the involved root were having adequate length \& sound periacipal status.

\section{Conclusion}

There was complete resolution of all symptoms which were present at first appointment. Our treatment resulted in the significant improvement of hopeless tooth. We can conclude that the proper case selection regeneration can be a valuable approach to increase the longevity of the tooth.

\section{Source of support}

Nil

\section{Conflicts of interest}

None.

\section{References}

1. American Association of Endodontists. Glossary of endodontic terms, 7th ed. Chicago, USA: American Association of Endodontists, 2003.

2. Kvinnsland I, Oswald RJ, Halse A, Grønningsaeter AG (1989) A clinical and roentgenological study of 55 cases of root perforation. Int Endod J 22: 75-84. [Crossref]

3. Nicholls E (1962) Treatment of traumatic perforations of the pulp cavity. Oral Surg Oral Med Oral Pathol 15: 603-612. [Crossref]
4. Abou-Rass M, Frank AL, Glick DH (1980) The anticurvature filing method to prepare the curved root canal. J Am Dent Assoc 101: 792-794. [Crossref]

5. Charrier M, Medioni E (2007) Microleakage of three filling materials for furcation perforation. Eur Cell Mater 13: 9.

6. Arabaci T, Ciçek Y, Canakçi CF (2007) Sonic and ultrasonic scalers in periodontal treatment: a review. Int J Dent Hyg 5: 2-12. [Crossref]

7. Al-Shammari KF, Kazor CE, Wang HL (2001) Molar root anatomy and management of furcation defects. J Clin Periodontol 28: 730-740. [Crossref]

8. Qazi SS, Manzoor MA, Khan HH, Arjumand B, Qureshi R (2007) Biphasic resection of a mandibular molar. J Coll Physicians Surg Pak 17: 294-296. [Crossref]

9. Divyashree P, Gujjari SK, Shah M, Ravi K (2012) Periodontal management of a furcation defect due to iatrogenic perforation. Indian J Multidiscipl Dent 3: 643.

10. Tsesis I, Fuss Z (2006) Diagnosis and treatment of accidental root perforations. Endod Topics 13: 95-107.

11. Sinai IH (1977) Endodontic perforations: their prognosis and treatment. $J$ Am Dent Assoc 95: 90-95. [Crossref]

12. Gutmann JL, Harrison JW (1991) Surgical Endodontics. Boston, MA: Blackwell Scienti?c Publications; pp. 409.

13. Strömberg T, Hasselgren G, Bergstedt H (1972) Endodontic treatment of traumatic root perforations in man. A clinical and roentgenological follow-up study. Svensk tandläkare tidskrift. Swedish Dent J 65: 457.

14. Rud J, Andreasen JO, Jensen JM (1972) A multivariate analysis of the influence of various factors upon healing after endodontic surgery. Int J Oral Surg 1: 258-271.

15. Rud J, Rud V, Munksgaard EC (1998) Retrograde sealing of accidental root perforations with dentin-bonded composite resin. J Endod 24: 671-677. [Crossref]

16. Oswald RJ (1979) Procedural accidents and their repair. Dent Clin North Am 23: 593 616. [Crossref]

17. Goon WW, Lundergan WP (1995) Redemption of a perforated furcation with a multidisciplinary treatment approach. J Endod 21: 576-579.

18. Barkhordar RA, Javid B (2000) Treatment of endodontic perforations by guided tissue regeneration. Gen Dent 48: 422-426. [Crossref]

19. Breault LG, Fowler EB, Primack MC. Endodontic perforation repair with resinionomer: a case report. J Contemp Dental Pract 1: 1-7.

20. Duggins LD, Clay JR, Himel VT, Dean JW (1994) A combined endodontic retrofill and periodontal guided tissue regeneration technique for the repair of molar endodontic furcation perforations: report of a case. Quintessence Int 25: 109-114. [Crossref]

21. DeSanctis M, Murphy KG (2000) The role of resective periodontal surgery in the treatment of furcation defects. Periodontol 2000 22: 154-168. [Crossref]

22. Sato N. Periodontal surgery: A clinical atlas. USA: Quintessence Pub Co; 2000.

23. Farshchian F, Kaiser DA (1988) Restoration of the split molar: bicuspidization. Am J Dent 1:21-22.

Copyright: (C2018 Gufran K. This is an open-access article distributed under the terms of the Creative Commons Attribution License, which permits unrestricted use, distribution, and reproduction in any medium, provided the original author and source are credited. 